\title{
Associative unlearning as a function of degree of interpolated learning ${ }^{1,2}$
}

\author{
JOEL M. SANDAK, RUTGERS UNIVERSITY \\ BERTRAM E. GARSKOF, MICHIGAN STATE UNIVERSITY
}

This study investigated the unlearning of first list associations as a function of degree of interpolated learning. Ss received either $1,2,6,11$, or 21 trials of interpolated learning in the A-B, A-C paradigm. Immediately following $\mathrm{IL}$, retention of A-B associations was measured with a S-R matching test. Unlearning was found to increase with increasing IL trials.

Both response unavailability and associative unlearning have been demonstrated in the $A-B, A-C$ paradigm through the use of modified recall and $S-R$ matching tests (e.g., Barnes \& Underwood, 1959; McGovern, 1964). Only response unavailability thus far has been shown to depend on degree of interpolated learning (Barnes \& Underwood, 1959). In all but one of the studies employing the S-R matching test, degree of IL was not manipulated. Garskof (1964) reported a study in which it was found that S-R matching, following A-B, A-C learning, was not influenced by amount of $A-C$ learning. If the matching test measures strength of $\mathrm{A}-\mathrm{B}$ association it seems reasonable that amount of IL should influence matching errors. Should the Garskof (1964) finding be reliable, a considerable revision of the notion of associative unlearning would be necessary. Thus, we decided to redo the Garskof (1964) study to determine whether this rather surprising finding was replicable.

Method

Design. Ninety-six male and female Rutgers University undergraduate paid volunteers were assigned randomly to the experimental conditions. Each Slearned $10 \mathrm{CVC}$-adjective pairs to a criterion of one perfect repetition of the list (A-B). Each of $80 \mathrm{Ss}$ then learned a second list consisting of the 10 original CVCs paired with 10 new adjectives unrelated to the original adjectives $(A-C)$. Groups of 16 Ss were given either $1,2,6,11$, or $21 \mathrm{~A}-\mathrm{C}$ trials. The remaining $16 \mathrm{Ss}$ (controls) took the Meier Art Judgment Test (Meier, 1940) for a time equivalent to $21 \mathrm{~A}-\mathrm{C}$ trials. Eight males and eight females were randomly assigned to each condition in the experiment.

Materials. CVC syllables of from $0-20 \%$ association value were the stimuli (Glaze, 1928). Intralist and interlist stimulus similarity was minimized, with no syllable beginning with or ending with the same consonant. Responses were twenty two-syllable adjectives of $\mathrm{A}$ or AA frequency in the written language (Thorndike \& Lorge, 1944). Apparent response similarity in meaning was minimized by inspection. To reduce orthographic similarity, no two adjectives within a list began with the same letter.

Test booklets were prepared for the S-R matching task so that each page of the booklet contained one of the stimuli followed by a blank space. The pages of each booklet were shuffled before being stapled. Sheets containing first-list responses were also prepared.

There were two different CVC-adjective pairings for each $A-B$ and $A-C$ list. Each pairing served as list-1 and list-2 equally often. The two A-B and A-C pairings were used equally often as control Ss' only list to be learned. Four orders of items were presented to minimize serial learning.

Procedure. Learning lists were presented on a Lafayette memory drum at a 2:2 sec. rate with $4 \mathrm{sec}$. between trials and $1 \mathrm{~min}$. between lists. Standard paired-associate anticipation instructions were used. Ss were presented matching booklets and response sheets immediately after IL. Ss were instructed to write the appropriate response in the space provided in the booklet. No time limit was imposed but Ss were encouraged to spend only a few seconds on each page and were not permitted to return to a page once it had been turned.

\section{Results and Discussion}

List-1 Learning. Before the retention data could be examined it was necessary to determine whether the six groups differed in A-B Learning. Mean A-B trials to criterion over all groups was 13.75 with a range of 13.00-14.38. Analysis of variance indicated no significant source of variance $(F<1.00)$.

Retention Data. Table 1 presents the mean number of correct pairings for all conditions. These data were converted to proportions, normalized, and their variances made homogeneous be means of an arcsine transformation. An analysis of variance of the transformed data indicated a significant between groups effect $(F=2.46, d f=5 / 90, p<.05)$. Dunnett's tests showed that the 11 and 21 IL trials groups were significantly different from the A-B control group $(p<$ $.05)$. No other comparisons were significant.

Table 1. Mean Number Correct on S-R Matching Test

\begin{tabular}{lcccccc}
\multicolumn{7}{c}{ A-B } \\
& $\begin{array}{c}7 \\
\text { Control }\end{array}$ & 1 & 2 & 6 & 11 & 21 \\
\cline { 2 - 7 } $\bar{X}$ & 9.81 & 9.50 & 9.38 & 9.06 & 8.56 & 8.56 \\
SD & 0.55 & 1.92 & 1.02 & 1.10 & 1.92 & 1.46 \\
\hline
\end{tabular}


Thus, with greater amounts of IL Ss made a greater number of S-R matching errors, and there were more errors in these groups than in the group which had no IL. From these data it can be said that associative unlearning occurs in the A-B, A-C paradigm as a function of degree of IL. The present results are more sensible in the light of unlearning theory but are in partial conflict with the data reported in Garskof (1964). Further research is needed before a firm conclusion can be drawn with regard to this issue.

\section{References}

Bames, J. M., \& Underwood, B. J. Fate of first-list associations in transfer theory. J. exp. Psychol., 1959, 58, 97-105.

Garskof, B. E. Unlearning in recognition matching as a function of degree of second-list learning. Paper read at Psychonomic Society Meeting, 1964.

Glaze, J. A. The association value of nonsense syllables. $J$. genet. Psychol., 1928, 35, 255-269.

McGovern, J. B. Extinction of associations in four transfer paradigms. Psychol. Monogr., 1964, 78, No. 16 (Whole No. 593).

Meier, N. C. Meier art tests: I-art judgement. State University of Iowa: Bureau of Educational Research \& Service, 1940.

Thomdike, E. L., \& Lorge, I. The teacher's word book of 30,000 words. New York: Bureau of Pub., Teachers College, Columbia University, 1944.

\section{Notes}

1. The investigation was supported by a research grant, MH-11503 from the National Institute of Mental Health, Public Health Service. 2. This paper is based on a thesis submitted to the Graduate Faculty of Rutgers University by the first author in partial fulfillment of the requirements for the $M$. $S$. degree. 